\title{
Kafka, Winnicott e a Boneca Viajante: perder, narrar, resgatar*1
}

\author{
Claudia Mazzini Perrotta*2 \\ Elisa Maria de Ulhôa Cintra*3
}

Este artigo apresenta uma reflexão sobre o livro Kafka e a Boneca Viajante, a partir de conceitos desenvolvidos por $D$. $W$. Winnicott, tais como objetos e fenômenos transicionais, jogo do rabisco, espaço potencial, importância do brincar, fazendo-se, ainda, uma analogia com a constituição do vínculo terapeuta e paciente. A reflexão proposta permitiu ressaltar o quanto processos analíticos podem levar à vivência de experiências emocionais transformadoras, convertendo objetos perdidos nas diversas formas de cultura.

Palavras-chave: Winnicott, objeto transicional, espaço potencial, campo cultural

${ }^{* 1} \mathrm{O}$ artigo baseia-se na tese acadêmica intitulada Processos criativos no espaço terapêutico da escrita: um diálogo com D.W. Winnicott, Clare Winnicott e Marion Milner. Perrotta, C. M. (2014). Programa de Psicologia Clínica. Pontifícia Universidade Católica de São Paulo - PUC-SP, São Paulo.

*2 Pontifícia Universidade Católica de São Paulo - PUC-SP (São Paulo, SP, Br).

*33 Pontifícia Universidade Católica de São Paulo - PUC-SP (São Paulo, SP, Br). 
Em uma superposição de narrativas, tempos e ilusões, o livro Kafka e a Boneca Viajante, de Jordi Sierra i Fabra (2006), reconta uma lenda: em 1923, um ano antes de falecer em um sanatório da Áustria, Kafka teria se dedicado a escrever cartas a uma garotinha que encontrara em um parque de Berlim. Ela chorava convulsivamente por ter perdido sua boneca, e, para consolá-la, o escritor tcheco inventou que a boneca havia ido viajar. Autodenominando-se carteiro de bonecas, durante três semanas se encontrou com a garotinha no mesmo parque, sempre na mesma hora, para lhe entregar a ansiada correspondência.

Na narrativa criada por Sierra i Fabra, as cartas da boneca viajante, de nome Brígida, chegavam de Londres, Paris, Veneza, Saara, Índia, Japão, México... - pouco importava a lógica, ou a falta dela, em termos de espaço geográfico e tempo; nas mãos de Kafka, "a boneca fizera o mundo ficar pequeno" (p. 74). Além da descrição minuciosa das maravilhas de todos esses lugares, as cartas eram entremeadas com justificativas pela partida repentina: “(...) as despedidas são tristes, e eu não queria que você chorasse nem tentasse me convencer a ficar mais um pouco". Traziam também ensinamentos simples: "Elsi, você deve saber que viver é seguir em frente, aproveitar cada momento"; reconhecimento e conforto: "Você cuidou de mim, me ensinou muitas coisas, me amou e me fez ser uma boa boneca (...) a partida foi triste por deixá-la, mas bonita porque graças a você sou livre para fazer isso" (pp. 48-49).

O personagem Kafka ia assim procurando ajustar seu idioma, buscando uma linguagem simples, de modo a tornar tudo verossímil, de acordo com as possibilidades do jogo imaginativo: as cartas traziam os selos dos locais visitados por Brígida e os envelopes sempre estavam lacrados. Além disso, as palavras eram de uma filha que deixa a casa dos pais para se experimentar, com a reserva de amor que lhe proporcionaram, sentindo-se potente para enfrentar os reveses da vida. Assim, ao mesmo tempo em que acolhia o sofrimento de sua pequena amiga, Kafka sinalizava que ela havia experimentado com sua boneca exercer a função de cuidado maternal, por sinal, de modo suficientemente bom...

$\mathrm{Na}$ verdade, o escritor Franz Kafka e a garotinha Elsi haviam se tornado cúmplices de um grande segredo. Tomados pelo magnetismo da história, 


\section{MOVIMENTOS LITERÁRIOS}

contaminados pela vivacidade de Brígida e seu espírito aventureiro, viviam o sonho de viajar, o sonho de poetas e cegos - aqueles que podem ver na escuridão: "Sem sonhos, somos apenas corpos perdidos vagando na rotina" (p. 85).

\section{Travessias: jogo do rabisco, objetos e fenômenos transicionais}

Kafka e a Boneca Viajante pode ser chamada de uma narrativa autenticamente winnicottiana, tantos são os conceitos, e valores, que guarda da obra do autor.

Era verão em Berlim, e o Parque Steglitz seguia frequentado pelas mais variadas pessoas, casais, velhos, soldados, babás e, entre elas, o escritor e a menina. $\mathrm{O}$ encontro, ou o espaço potencial para a sustentação do sofrimento de Elsi, para que se refizesse da dor da perda de seu objeto transicional, ou para que elaborasse o luto da perda da infância, com presença amorosa, ganhou contornos justamente em um banco desse parque. Nele, Franz Kafka e Elsi estabeleceram uma aliança de trabalho: assíduos e comprometidos, compareciam no mesmo lugar e na mesma hora para realizar uma tarefa - ler ou degustar as cartas de Brígida. Mas, embora estivessem presentes em um espaço e tempo pertencentes à realidade compartilhada, os dois permaneciam apartados, entregues a um espaço e tempo próprios de outra realidade, outro campo, o estético, ou em outra área de experiência, intermediária: “(...) lugar de repouso para o indivíduo empenhado na perpétua tarefa humana de manter as realidades interna e externa separadas, ainda que inter-relacionadas" (Winnicott, 1953/1975, p. 15).

O lugar de repouso era mesmo a correspondência de Brígida, criada a partir do que poderíamos chamar, fazendo uma analogia, de um intenso jogo de rabisco (squiggle game, Winnicott, 1964-1968/1994) realizado entre Kafka e Elsi. Tendo como base o brincar, Winnicott destacou que a técnica squiggle game poderia ser utilizada no trabalho que denominou "consulta psicoterapêutica", em que estaria em jogo "certa capacidade de acreditar na obtenção de auxílio e de confiar naquele que o oferece". Aqui, antes de interpretar, o terapeuta necessitaria ser capaz de aprender com o paciente, a ele proporcionando um relacionamento humano natural; já o paciente se surpreenderia "com a produção de ideias e sentimentos que não estiveram anteriormente integrados na personalidade total". Esse tipo de intervenção seria mais indicado a crianças ou adultos que provêm de ambientes suficientemente bons, mas que, em dado momento, necessitam de uma pequena ajuda para retomar o curso de seu processo de amadurecimento. A técnica teria a função de facilitar o estabelecimento de uma relação de confiança entre terapeuta e paciente, de modo que este reavive sua esperança de ter uma necessidade atendida, mesmo que referente apenas a determinado aspecto da personalidade. $\mathrm{O}$ autor adverte, no entanto, que não 
se trata de uma "técnica estabelecida com regras e regulamentos", caracterizando-se mais como "um jogo natural que duas pessoas podem jogar" (pp. 230-231).

Duas pessoas: Kafka e Elsi. Capturado pelo choro convulso da menina, aflita em sua dor e solidão, Kafka parou diante dela, mas não sabia o que dizer. Até que sua mente de escritor teve uma ideia: "Sua boneca não se perdeu, ela foi viajar" (Sierra i Fabra, 2006, p. 21). E assim fez o primeiro rabisco. "Aqueles segundos eram decisivos. A menina podia tomá-lo por louco. Mas também podia aferrar-se à esperança. E a esperança era mais necessária que a realidade" (p. 24). De fato, o jogo só foi possível porque Elsi era uma menina saudável — era capaz de brincar, de sentir prazer com a brincadeira, ou de manter-se na área intermediária entre o campo subjetivo e o que é objetivamente percebido, e ainda de aceitar diferença e similaridade - base para o estabelecimento da função simbólica (Winnicott, 1975). E também porque encontrou em Kafka um adulto/terapeuta disponível para uma breve e reparadora interação, ofertando-lhe sua própria engenhosidade e provisões para o jogo, nele entrando com seus próprios recursos e condições.

Aconteceu então o que Winnicott caracteriza como "sobreposição parcial da área de brinquedo da criança e da área de brinquedo do adulto ou terapeuta" (Winnicott, 1964-1968/1994, p. 243). Havia, pois, similaridade nas experiências ilusórias de ambos, o que certamente facilitou o encontro. Também podemos supor que o encontro e o jogo foram possíveis porque Elsi trazia na memória experiências positivas de constituição de si, contando com um ambiente suficientemente bom, que lhe permitira não só internalizar como exercer funções de cuidado, agora especialmente dispensadas à Brígida - algo muito tematizado nas cartas, como forma de consolar a menina pela perda e sinalizar um futuro que ela também alcançaria: "... para todo mundo chega a hora de deixar a casa dos pais, para viajar, conhecer a vida, o mundo, talvez um futuro delicioso" (Sierra i Fabra, 2006, p. 25).

Esse ambiente, representado pela mãe, também ganha lugar na narrativa. Preocupada com a filha, a mãe de Elsi aparece no parque para conhecer o carteiro de bonecas — terna, ela respalda o jogo, sem nele interferir, mantendo-se apenas como testemunha, como devem muitas vezes fazer as mães, e os terapeutas. Não é difícil imaginá-la contendo o bebê Elsi nos braços, amparando-a em sua precariedade originária, presença silenciosa, disponível para entrar em sintonia com suas necessidades e buscando atendê-las. E qual teria sido a primeira posse não eu de Elsi, que lhe permitira viajar do sentido mais subjetivo, da realidade interna, à realidade compartilhada? Qual a qualidade estética desse veículo que escolhera e manejara para alcançar a próxima etapa da existência? Uma fraldinha macia que ganhara da mãe logo que nasceu, ou a própria Brígida? Certamente, uma mãe capaz de "deixar um objeto real permanecer exatamente onde o bebê está alucinando um objeto, de maneira que ele fica com a ilusão de que o mundo pode ser criado e de que o que é criado é o mundo" (Winnicott, 1959/1994, p. 44). Um objeto que 


\section{MOVIMENTOS LITERÁRIOS}

faz parte da realidade compartilhada, embora a criança o perceba também como fazendo parte de sua realidade interna, tendo, portanto, algum controle sobre ele, embora ele não seja, apenas, fruto de alucinação.

De fato, cada criança costuma criar seu próprio objeto, a partir de aspectos sensoriais que lhe são atraentes, como texturas, maciez ou dureza, e também busca nomeá-los de forma singular. Trata-se, de acordo com Safra (2004, informação verbal), da construção estética do modo de ser, de estilos e de espaços pessoais: "há certa linhagem na maneira como a pessoa compõe seu mundo". O autor destaca ainda que há, neste momento de criação do objeto transicional, um reposicionamento da questão da ilusão: "se no primeiro sentido subjetivo da realidade, a ilusão é continuidade de si, neste momento, uma porção menor do mundo que é recolhida está subordinada à capacidade de criar". A ilusão é colocada, então, no objeto transicional, que não só passa a ser um ente animado, mas sempre implica ruptura com o meio: "Para possuir o objeto transicional, tem de haver a possibilidade de desconstruir o que foi ofertado" (Ibid.). E adverte que, embora o objeto transicional se configure como símbolo (encontrar o familiar no não familiar), ou seja, pode representar a mãe, ajudando a sustentar a angústia dos momentos de separação, ele é ainda mais importante por possibilitar outro lugar à criança, por facilitar o percurso entre os sentidos de realidade, por permitir que dê um destino à própria existência e, ainda, por possibilitar que atribua sentidos ao vivido.

Como bom parceiro, e terapeuta, Kafka acompanhou Elsi no momento de abandono do objeto transicional, que se espalha então para entrada no campo cultural: ambos criaram personagens, rompendo, assim, os sentidos originários desses objetos, a eles atribuindo outros estatutos - boneca viajante, menina que vira mãe, escritor que vira carteiro. Até que completaram o percurso e chegaram ao outro lado da ponte, transformados e com novas aberturas para novas experiências. E neste aspecto, de narrativa do processo de encontro, "Kafka e a Boneca Viajante" também nos remete a Winnicott.

No texto "A observação de bebês numa situação padronizada", Winnicott (1941/2000) caracteriza três momentos típicos de relação com objeto, no caso, uma espátula, apresentada aos bebês entre cinco e 13 meses de idade. Com essa técnica simples, conseguia observar a maneira como as mães lidavam com seus filhos, se eram ansiosas, se tinham ou não muitas restrições morais quanto a pôr coisas na boca, e também a forma como os bebês se relacionavam com a comida e com as pessoas, representadas pela espátula. A partir da oferta desse objeto, que apenas ficava disponível de modo que o bebê pudesse alcançá-lo, sem interferência dos adultos, o pediatra e psicanalista observou certa "sequência normal de eventos" que se repetia. Assim, em um primeiro estágio, denominado "período de hesitação", o bebê parece viver um dilema, qual seja, entregar-se ao desejo pelo objeto ou desinteressar-se definitivamente dele. $\mathrm{O}$ segundo, quando a 
criança assume seu desejo pela espátula, é anunciado por mudanças corporais, em especial na região oral, sendo seguidas pela exploração do objeto, que é então mastigado, e depois manipulado de diversas formas: "O bebê agora parece sentir que a espátula está em sua posse, talvez em seu poder e certamente disponível para propósitos de autoexpressão" (p. 114). Por fim, o terceiro estágio se caracteriza pelo abandono do objeto, quando, depois de mais algumas explorações, o bebê perde o interesse e procura algum outro objeto. Aqui, Winnicott se refere a Freud (1920), especificamente à digressão sobre o jogo do carretel, destacando o quanto, neste momento, o bebê se sente corajoso por conseguir se livrar da espátula (ou carretel), que, na verdade, representaria a mãe: "quando a mãe se afasta, trata-se não apenas da perda da mãe externa e real, mas também de um teste para o relacionamento do menino com sua mãe interna" (p. 130, grifo do autor). A mãe interna, na verdade, é reflexo de seus próprios sentimentos, amorosos ou, ao contrário, aterrorizantes, alternando-se entre um e outro.

Winnicott (1941/2000) destaca que a experiência com a espátula, o desejo de dela tomar posse, sem que isso altere a estabilidade ambiental, se configuraria para a criança como uma "aula sobre o objeto", tendo "valor terapêutico". Repetidas no tempo, essas experiências gratificantes tornam-se reasseguradoras de confiança nas pessoas e no mundo externo, trazendo segurança interna e crença nas coisas boas e em bons relacionamentos: “(...) por meio de seus atos ao brincar, [a criança] conseguiu efetuar a reparação e trazer de volta à vida as pessoas cuja perda tanto teme" (pp. 128-131). Com base em Melanie Klein, ainda destaca o fato de a realidade interna sempre ser constituída e enriquecida pelas experiências vividas com os objetos externos, e vice-versa, ou seja, "o mundo externo está sendo constantemente percebido pelo indivíduo, e seus relacionamentos externos constantemente enriquecidos, dada a existência, nele, de um mundo interno cheio de vida" (p. 122).

Mas vamos voltar às nossas personagens, agora enriquecidos com mais estas contribuições de Winnicott — lembrando que o autor acentuou a importância de uma experiência ocorrer em toda a sua extensão, ou o valor terapêutico de se completar, algo também presente em processos de análise: "cada interpretação é um objeto reluzente que excita a voracidade do paciente" (Winnicott, 1941/2000, p. 129). Considerando que o encontro entre Kafka e Elsi adquiriu valor terapêutico, de sustentação do sofrimento e frustração advindos da perda, podemos fazer uma analogia e concluir que, certamente, o objeto que excitava a voracidade de Elsi eram as cartas de Brígida. "Kafka e a Boneca Viajante" refaz todo o percurso do encontro - a hesitação da menina, que vimos estar saudável em seu processo de constituição, manifestou-se no início por meio das perguntas que dirigiu a Kafka: "Viajar? Para onde? Que carta?", e no olhar de incredulidade que lhe dirigiu. Mas Kafka sustentou aquele olhar "com sua melhor cara de jogador imaginário". Mesmo com a revelação de que Kafka era um carteiro de bonecas, as perguntas continuaram: 


\section{MOVIMENTOS LITERÁRIOS}

“Os carteiros não entregam as cartas nas casas?” (Sierra i Fabra, 2006, pp. 23-27). Mas Kafka parecia prevenido, ágil e perspicaz em suas respostas, tanto que Elsi finalmente abandonou a lógica mental e se entregou ao jogo: capaz de brincar, aceitou encontrar-se com ele no dia seguinte, para receber a primeira carta de Brígida.

A passagem para o segundo estágio foi marcada pelo gesto de pular do banco e se colocar diante de Kafka: "Finalmente venceu o passo que a separava de seu novo amigo e lhe deu um beijo no rosto... - Então, até amanhã — despediu-se" (p. 29). Haveria então uma continuidade, um amanhã, em que poderia se apossar das cartas, usá-las até o ponto de abandoná-las, o que significava também abandonar a própria boneca. Interessante que, em certo ponto da narrativa, depois de ter se autodenominado carteiro de bonecas e se comprometido a entregar a primeira correspondência à Elsi, Kafka procurou fazer uma pesquisa para saber um pouco mais sobre esse objeto que lhe era tão pouco familiar. Procurou então sua vizinha, que tinha uma filha da idade de sua amiguinha, e pediu que ela lhe mostrasse alguma boneca: ela the trouxe uma bem velha, com um olho só, cabelos e roupas imundos. Será que Brígida também estaria nesse estado deplorável? Talvez..., não sabemos. Mas sabemos que Elsi a havia perdido, e talvez seu sofrimento também portasse alguma culpa por esse descuido momentâneo. Por isso, o gesto de generosidade de Kafka, ou a função de cuidado que exercera naquele momento, ganha ainda maior importância pela possibilidade de, por meio da narrativa das viagens, Elsi fazer alguma reparação e assim seguir adiante, aliviada por não ter destruído seu objeto de afeição, ou sua mãe interna, que sobrevivera e com quem poderia então continuar a brincar.

Descuido, culpa, tristeza, ansiedade, reparação, alívio, possibilidade de esquecer o objeto e felicidade reconquistada — é assim que termina a história de Elsi. Brígida interrompeu a correspondência porque se apaixonou: "Gustav e eu somos marido e mulher (...) muito em breve, teremos filhos e filhas tão lindos como você (...). Não conseguiria isso sem seu amor" (p. 109). Por fim, Kafka presenteou sua amiguinha com uma nova boneca, de porcelana: “(...) É na infância que existem os finais felizes. Mas são muito mais necessários na maturidade os carteiros capazes de receber cartas que só um louco é capaz de escrever" (p. 114).

Mas de que "loucura" se trata? "Kafka e a Boneca Viajante" nos fornece elementos para também pensarmos a semelhança entre o trabalho de um escritor e o brincar infantil. ${ }^{1}$ Kafka elegeu a escrita para se expressar, realizar-se e aparecer

${ }^{1}$ No texto "Escritores criativos e devaneios", Freud (1908[1907]) já enuncia o trabalho de um escritor em analogia com o brincar infantil: “(...) a obra literária, como o devaneio, é uma continuação, ou um substituto, do que foi o brincar infantil” (p. 150). 
no mundo com seus temas, questões, visões e inquietudes. No momento, a brincadeira envolvia Elsi e Brígida, além do próprio Kafka, que assumia então duas novas identidades: boneca viajante e carteiro de bonecas. Mas essa ideia não surgiu de imediato. Diante das lágrimas sinceras, perguntou-se o que podia fazer: “(...) Não sabia o que dizer a uma menina. E muito menos a uma menina que chorava porque acabara de perder a boneca" (Sierra i Fabra, 2006, p. 20). Quis ir embora, com uma desculpa qualquer, um "sinto muito" impessoal, ou uma recomendação que, indiferentes, adultos costumam dirigir a crianças, sem atinar para a importância desse tipo de fenômeno. Porém, Kafka sabia do caráter mortal de sua doença, a tuberculose, e, certamente, isso o fez se tocar profundamente pelo sofrimento de Elsi, em plena dor de sua primeira grande perda, tão diferente da vivida pelo escritor e, ao mesmo tempo, tão próxima, uma vez que as experiências de luto mantêm entre si uma invisível solidariedade. Mas, talvez, algo além da empatia o tenha capturado: a possibilidade de, mais uma vez, criar uma história — ele que vinha se sentindo um velho inútil por ter precisado se aposentar recentemente. Ele que havia pedido a um amigo ${ }^{2}$ que, após sua morte, destruísse todos seus textos inéditos, o que felizmente não se concretizou, sinalizando o intenso conflito que vivia com suas criações. Também para ele "estava em jogo uma esperança. O que há de mais sagrado na vida” (p. 32).

Com a vivacidade renovada, contaminado pela força da relação de uma menina com sua boneca, foi tomado por certo nervosismo. Era escritor, mas nunca havia escrito carta de boneca, só carta ao próprio pai, que, por sinal, jamais entregara... "Sua cabeça fervilhava. Pensava em Brígida, em Elsi, no primeiro lugar em que a boneca teria desembarcado, na forma como escreveria para sua dona. Chegou a sua rua, a sua casa, tomado pela mesma febre" (p. 33). Numa palavra: antes de escrever, todo o corpo de Kafka já se entregara à história. "Preciso escrever", disse à sua companheira Dora antes de se fechar em seu escritório, com a "expressão alucinada" típica desses momentos: "Vamos lá, Brígida", clamou diante das folhas em branco. Mais do que um desejo, tratava-se, pois, de uma necessidade. Além do mais, como bem ressalta Winnicott (1968/1994, p. 162), o brinquedo é sempre excitante, “(...) não por causa do pano de fundo do instinto, mas por causa da precariedade que lhe é inerente, uma vez que sempre lida com o fio da navalha existente entre o subjetivo e o que é objetivamente percebido" (grifo do autor).

Agora, tudo dependeria da forma como Elsi, sua única leitora, receberia aquela primeira correspondência. No dia seguinte, já com a menina ao seu lado, e preparando-se para começar a leitura, sentiu-se ridículo. Parecia haver um grande abismo entre o momento solitário de entrega febril e excitante à escrita e aquele, de

${ }^{2}$ Trata-se de Max Brod, também escritor, nascido em Praga e biógrafo de Kafka. 


\section{MOVIMENTOS LITERÁRIOS}

compartilhar sua composição - algo que todos nós que nos dedicamos à tarefa de escrever conhecemos muito bem e que, como pontuou Marion Milner (1957/1991), trata-se de uma das ansiedades típicas do processo criativo, qual seja, a possibilidade de não sermos recebidos ou reconhecidos pelo outro a quem apresentamos nossa produção com a mesma excitabilidade que nos tomou no momento da concepção: "Quando acabou de ler a carta, Franz Kafka pensou como, de repente, o resultado parecia efêmero, comparado às muitas horas investidas naquela simples redação" (Sierra i Fabra, 2006, p. 51).

Mas, como vimos, Elsi entrou no jogo, nele imprimindo seu estilo de ser, de brincar, tanto que ofertou alimento para uma próxima carta, cobrando sua entrega ao carteiro de bonecas, em quem já confiava inteiramente: “(...) A carta tinha sido um parto. Com dor. Um parto carregado de espinhos com a melhor das intenções: devolver a paz à alma de uma menina ferida" (p. 54). Novo desafio - será que conseguiria superar ou ao menos manter a perfeição da primeira carta? Mais uma vez, através do personagem Franz Kafka, Sierra i Fabra (2006) emoldura outra inquietação, por vezes paralisante, de um criador/escritor: os recursos expressivos teriam se esgotado ou haveria ainda uma reserva de temas e palavras a serem compostas, combinadas em um todo harmonioso e instigante?

Estamos aqui diante de um paradoxo: as experiências positivas de produção acabada, que ganha o público e recebe ressonâncias, embora permaneçam como memória de acontecimentos bem-sucedidos, de potencialidade criativa realizada a contento, também trazem dúvidas sobre nossa real capacidade de gerar — para ir adiante na próxima ou futura produção, é preciso que desenvolvamos a condição de sustentar esse paradoxo. Como fez Kafka: Brígida agora voara a Paris: "O secreto autor do texto sorriu para si mesmo. (...) A pena voara com muito mais liberdade e as palavras tinham se encadeado como uma longa trança de emoções e sentimentos" (p. 60). O escritor se surpreende com sua própria condição, sendo então apresentado a facetas de si ainda desconhecidas. Na verdade, objeto cultural — escrita ou qualquer outra materialidade - é possibilidade de integração que só acontece quando somos capazes de sustentar essas dúvidas sobre nossa própria condição de autossuperação e as inquietações inerentes a todo e qualquer processo criativo que, por sinal, acomete mesmo os mais letrados ou renomados escritores/artistas. ${ }^{3}$

${ }^{3}$ Interessante como muitas pessoas que procuram o que denominamos espaço terapêutico da escrita, para trabalhar seus escritos, chegam se autodenominando doentes, disléxicos ou incompetentes para escrever, descrevendo "sintomas" semelhantes aos de Kafka, e de tantos outros artistas/ criadores: estado febril de difícil sustentação, pelo abismo entre o que se tem a dizer, por vezes tão claro no pensamento, mas que ainda precisa percorrer um árduo caminho até se realizar em outra 
Mas a capacidade de sustentação depende de boas parcerias, de alguém que nos acompanhe em nossas buscas e se disponha a nos receber em nosso idioma pessoal - e Elsi era mesmo uma boa anfitriã, afinal precisava muito ouvir a voz de sua boneca: "Franz Kafka não sentia mais o medo nem a inquietação do dia anterior (...). Ele havia escrito aquelas palavras tomado pelo magnetismo da história, entregue a cada sentimento que experimentava, e agora conseguia lê-las com a mesma devoção (pp. 61-62). E como escritor, cumpria-lhe a dura tarefa de encontrar um final para a história da boneca viajante. O sofrimento do ponto final, do abandono da espátula, de uma parte de si, a angústia do fim: "Franz Kafka olhou seus manuscritos (...). Sua obra não publicada, seu legado. Tão efêmero como seria sua vida” (p. 103). A não ser por Elsi e as cartas de Brígida:

Tocou as páginas. Acariciou as folhas de papel cheias de palavras corretamente escritas com sua letra bonita e miúda. Ele estava ali. De corpo e alma. O coração nu de qualquer escritor. E, no entanto, de repente, a única coisa que tinha alguma lógica nas últimas semanas eram as cartas de Brígida a Elsi. Aqueles romances que nunca veriam a luz, que nunca seriam lidos, careciam de outro sentido que não fosse testemunhal, o de sua passagem pela vida e pelo mundo. (Sierra i Fabra, 2006, pp. 103-104)

Lembramos aqui de um trecho de Winnicott (1983/1963), no texto "Comunicação e falta de comunicação levando ao estudo de certos opostos": "No artista podemos detectar um dilema inerente, que pertence à coexistência de duas tendências, a necessidade urgente de se comunicar e a necessidade ainda mais urgente de não ser decifrado" (p. 168). Tensão a ser sustentada durante toda vida, própria de sua tarefa de escritor...

A última carta deu tanto trabalho como a primeira, escrita e reescrita muitas e muitas vezes, tanto que chegou a decorá-la: "Não é a carta mais bonita que já leu?" (Sierra i Fabra, 2006, p. 109). Sim, a carta mais bonita, e Kafka, incorporando a voz da boneca viajante, tanto trabalhara para materializar essa beleza que sua mente, seu corpo e sua alma se esvaziaram — nem fome sentia, apenas leveza...

materialidade, a escrita, o que exige mais do que conhecimento das regras da língua ou ainda das regularidades dos diversos gêneros discursivos; frustração diante da reação dos interlocutores, nem sempre hospitaleiros ao idioma pessoal; briga com a própria materialidade escolhida para apresentar suas inquietações, que nem sempre se mostra maleável ao gesto pessoal. Cf. Perrotta, C. M. (2014) Processos criativos no espaço terapêutico da escrita: um diálogo com D.W. Winnicott, Clare Winnicott e Marion Milner.Tese. Programa de Pós Graduação em Psicologia Clínica. Pontifícia Universidade Católica de São Paulo. 


\section{MOVIMENTOS LITERÁRIOS}

\section{Similaridades com o processo analítico}

Assim como Kafka, para poder escutar seu paciente, o analista precisa estar próximo de sua condição mortal, de seus lutos. Precisa aninhar-se em seu corpo, em suas memórias, em sua condição existencial mais íntima e vulnerável.

Pensando em Elsi, talvez o ponto mais importante para sua travessia tenha sido o olhar de Kafka: "Sou vista, logo, existo", diria Winnicott (1967/1975). Em análise, este primeiro lugar de reconhecimento é necessário para criar um continente, antes da intervenção interpretativa. Sem sentir-se reconhecido, o paciente não consegue se sentir "real", e as interpretações não se tornam mutativas. Pois bem, Elsi se viu refletida e reconhecida nos olhos do escritor e, assim, pôde criar com ele um primeiro lugar para a elaboração da dor. As primeiras palavras de Kafka seguiram-se a essa significativa troca de olhares: "Sua boneca não desapareceu; ela foi viajar" - um convite para colocar-se em movimento. Também durante uma análise somos enviados a outros tempos e lugares, em um constante desalojamento da posição que ocupamos - o trabalho exige este "colocar-se em marcha", percorrendo múltiplas direções e a sequência crescente de aproximações e afastamentos, hesitações e envolvimento. É preciso reconhecer, refletir, ressoar.

Quem eram Kafka e Elsi antes do encontro no Parque Steglitz? Quem seriam paciente e terapeuta? Esse "antes" vai desaparecendo, dando lugar a novas identificações e novos sujeitos psíquicos. Ambos celebram, juntos, a morte simbólica e o luto no processo de constituição e renovação de si. É isso que o processo analítico promete: o advento de um sujeito psíquico, de modo semelhante ao que Winnicott (1975) afirma ao pensar nos objetos e fenômenos transicionais. Como vimos, mais importante que o objeto em si é a jornada do subjetivo ao objetivo, do eu ao outro - perdido o objeto, é preciso convertê-lo, de forma irradiante, nas diversas formas de cultura. No caso de Elsi e de Kafka, a perda deu lugar à narrativa, o que significa, ao mesmo tempo, negar e afirmar tudo que foi vivido no corpo a corpo, com a mãe e com a boneca. A análise também possibilita esse movimento simultâneo de afirmação e negação. E é isto que torna possível viver uma experiência emocional e aprender com ela.

Porém, a tarefa de aceitar os limites da realidade nunca chega a seu termo, e ninguém pode ser liberado da exigência de articular as realidades interna e a externa. É, pois, um grande alívio quando podemos preencher a área intermediária de experiência com o sonhar, o brincar e o fazer artístico. O mesmo se pode dizer do processo analítico: evocação de outros tempos e lugares, apela ao "outrora", ao futuro do pretérito, ao passado imperfeito, ao perfeito do pretérito, um tempo mítico, de infinitas potencialidades. Algo análogo ao "era uma vez" dos contos de fadas. 
Assim como fez Kafka, cabe ao analista, então, "trazer o paciente da condição de não conseguir brincar para outra, em que ele consegue brincar" (Winnicott, 1975, p. 59). E para isso, precisa desenvolver a capacidade de ser criativo, de modo a liberar o trabalho da imaginação - criar o mundo e torná-lo significativo e real, de modo vivaz, polissêmico. Com isso, Elsi e Kafka, paciente e terapeuta, inauguram um novo lugar, pleno de sentidos, de modo que as experiências, disruptivas ou não, possam ser integradas verdadeiramente, transformando-se em histórias que podem ser narradas e, assim, ressignificadas. É o que fez Sierra i Fabra. É o que fazemos em nossos espaços terapêuticos.

\section{Referências}

Freud, S. (1976). Escritores criativos e devaneios. In Edição Standard Brasileira das Obras Psicológicas Completas de Sigmund Freud (Vol. IX, pp. 145-158). Rio de Janeiro: Imago. (Trabalho original publicado em 1908[1907]).

Milner, M. (1991). A ordenação do caos. In A loucura suprimida do homem são (pp. 216-232). Rio de Janeiro: Imago. (Trabalho original publicado em 1957).

Perrotta, C. M. (2014). Processos criativos no espaço terapêutico da escrita: um diálogo com D.W. Winnicott, Clare Winnicott e Marion Milner. Tese de Doutorado em Psicologia Clínica. Pontifícia Universidade Católica de São Paulo - PUC-SP, São Paulo.

Safra, G. (2004). Fenômenos e objetos transicionais. Aula ministrada para o concurso de Professor Titular na USP - 23 de setembro de 2004.

Sierra i Fabra, J. (2006). Kafka e a Boneca Viajante. São Paulo: Martins Fontes.

Winnicott, D. W. (1975). Objetos transicionais e fenômenos transicionais. In O brincar e a realidade (pp. 13-44). Rio de Janeiro: Imago. (Trabalho original publicado em 1953).

Winnicott, D. W. (1975). O papel de espelho da mãe e da família no desenvolvimento infantil. In O brincar e a realidade (pp. 153-162). Rio de Janeiro: Imago. (Trabalho original publicado em 1967).

Winnicott, D. W. (1983). Comunicação e falta de comunicação levando ao estudo de certos opostos. In O ambiente e os processos de maturação (pp. 163-174). Porto Alegre: ArtMed. (Trabalho original publicado em 1963).

Winnicott, D. W. (1994). O destino do objeto transicional. In C. Winnicott, R. Shepherd, \& M. Davis (Orgs.). Explorações psicanaliticas D.W. Winnicott (pp. 44-48). Porto Alegre: Artes Médicas. (Trabalho original publicado em 1959).

Winnicott, D. W. (1994). O jogo do rabisco. In C. Winnicott, R. Shepherd, \& M. Davis (Orgs.). Explorações psicanaliticas D.W. Winnicott (pp. 230-243). Porto Alegre: Artes Médicas. (Trabalho original publicado em 1964-68).

Winnicott, D. W. (1994). O brincar e a cultura. In C. Winnicott, R. Shepherd, \& M. Davis (Orgs.). Explorações psicanalíticas D.W. Winnicott (pp. 160-162). Porto Alegre: Artes Médicas. (Trabalho original publicado em 1968). 


\section{MOVIMENTOS LITERÁRIOS}

Winnicott, D. W. (2000). A observação de bebês numa situação padronizada. In Da pediatria à psicanálise (pp. 112-132). Rio de Janeiro: Imago. (Trabalho original publicado em 1941).

\section{Resumos}

(Kafka, Winnicott and the Traveling Doll: loe, tell, rescue)

This paper consists of a reflection on the book "Kafka and the Traveling Doll," by Jordi Sierra i Fabra (2006). The book is based on Winnicottian concepts such as transitional objects and transitional phenomena, potential space, the importance of playing, and the construction of the relationship between analyst and patient. This reflection shows that the analytic process gives rise to transformative emotional experiences that can modify lost objects into different cultural phenomena.

Key words: Winnicott, transitional object, potential space, cultural field

(Kafka, Winnicott et La Poupée Voyageuse: perdre, raconter, récupérer)

Cet article propose une réflexion sur le livre "Kafka et la poupée voyageuse", de Jordi Sierra i Fabra (2006), construite à partir des concepts winnicottiens: objets et phénomènes transitionnels, jeu du gribouillis, espace potentiel, l'importance du jeu. Nous suggérons d'ailleurs une analogie de la construction du lien entre l'analyste et le patient. Notre réflexion met en relief à quel point le processus analytique peut engendrer des expériences émotionnelles transformatrices en changeant les objets perdus en diverses formes culturelles.

Mots clés: Winnicott, objet transitionel, espace potentiel, champ culturel

(Kafka, Winnicott y la Muñeca Viajera: perder, narrar, recuperar)

Este artículo apresenta una reflexión en torno del libro "Kafka y la Muñeca Viajera", a partir de los conceptos desarrollados por DW Winnicott, como objeto y fenómeno transicionales, el juego de garabatos, espacio potencial, importancia del jugar; también se hace una analogía con la creación del vínculo terapeuta y paciente. Esta reflexión ha permitido enfatizar que los procesos de análisis pueden conducir a experiencias emocionales transformadoras, con la conversión de los objetos perdidos en las diversas formas de cultura.

Palabras claves: Winnicott, objeto transicional, espacio potencial, ámbito cultural

(Kafka, Winnicott und die reisende Puppe. Verlieren, Berichten, Wiederherstellen) In diesem Beitrag wird eine Reflexion über das Buch Kafkas Puppe vorgestellt. Ausgangspunkt sind die von D. W. Winnicott entwickelten Begriffe, wie Übergangsobjekte und Übergangsphänomene, Kritzelspiel, potentieller Raum, 
Bedeutung des Spielens, sowie eine Analogie zu Therapeut und Patient Verbindung. Die vorgeschlagene Reflexion erlaubte hervorzuheben, wie sehr analytische Prozesse zum Erleben von verwandelnden emotionalen Erfahrungen führen kann, indem sie verloren gegangene Objekte in verschiedene Kulturformen verwandeln.

Schlüsselwörter: Winnicott, Übergangsobjekte, potentieller Raum, Kulturraum

Citação/Citation: Perrotta, C.M. \& Cintra, E.M.de U. (2014, dezembro). Kafka, Winnicott e a Boneca Viajante. Revista Latinoamericana de Psicopatologia Fundamental, 17(4), 943-956.

Editor do artigo/Editor: Dr. Ricardo Telles de Deus

Recebido/Received: 28.9.2014/9.28.2014 Aceito/Accepted: 25.10 .2014 / 10.25.2014

Copyright: (C) 2009 Associação Universitária de Pesquisa em Psicopatologia Fundamental/ University Association for Research in Fundamental Psychopathology. Este é um artigo de livre acesso, que permite uso irrestrito, distribuição e reprodução em qualquer meio, desde que o autor e a fonte sejam citados / This is an open-access article, which permits unrestricted use, distribution, and reproduction in any medium, provided the original author and source are credited.

Financiamento/Funding: As autoras declaram não ter sido financiadas ou apoiadas / The authors have no support or funding to report.

Conflito de interesses/Conflict of interest: As autoras declaram que não há conflito de interesses / The authors have no conflict of interest to declare.

\section{Claudia Mazzini Perrotta}

Doutora em Psicologia Clínica pela Pontifícia Universidade Católica de São Paulo PUC-SP (São Paulo, SP, Br).

Rua Arthur de Azevedo, 1537/103

05404-014 São Paulo, SP, Br

e-mail: claper@attglobal.net

e-mail: claper.coda@gmail.com

\section{Elisa Maria de Ulhôa Cintra}

Doutora em Psicologia Clínica pela Pontifícia Universidade Católica de São Paulo - PUC-SP (São Paulo, SP, Br).

Rua Vargem do Cedro, 201/112

01252-050 São Paulo, SP, Br

e-mail: elcintra01@gmail.com 